SAND89-2563

Unlimited Release

Distribution

Printed September 1990

\title{
Evaluation of Commercially Available Lighting Design Software
}

\author{
Donna G. McConnell \\ Safeguards Technology Development Division \\ Sandia National Laboratories \\ Albuquerque, NM 87185
}

\begin{abstract}
This report addresses the need for commercially available lighting design computer programs and evaluates several of these programs. Sandia National Laboratories uses these programs to provide lighting designs for exterior closed-circuit television camera intrusion detection assessment for high-security perimeters.
\end{abstract}




\section{Acknowledgments}

I wish to thank D. S. Miyoshi (5240), B. J. Steele (5249), D. A. Greenwoll (5212), J. F. Chapek (5245), J. C. Matter (5212), all of Sandia National Laboratories, and D. A. Smith of EG\&G/EM for their technical support and for their help in editing this report. 


\section{Contents}

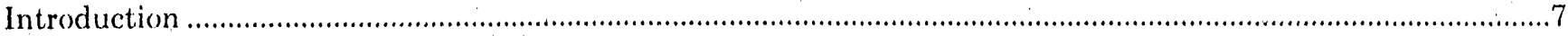

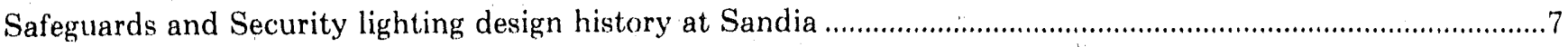

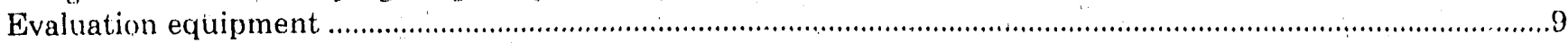

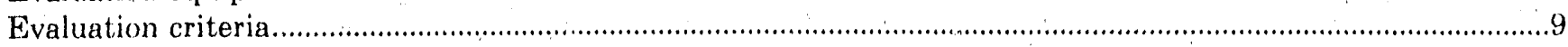

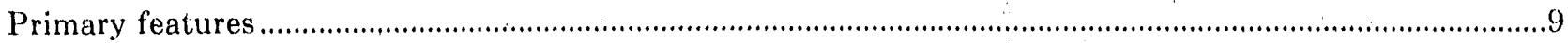

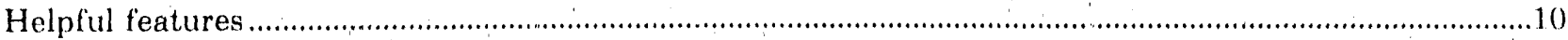

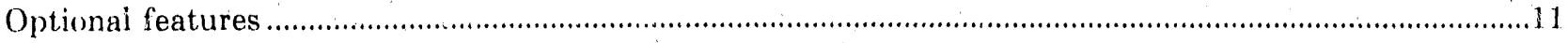

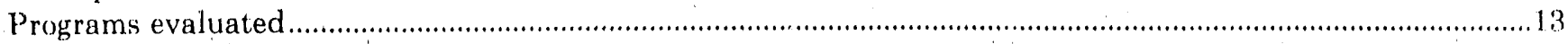

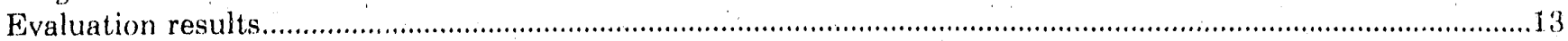

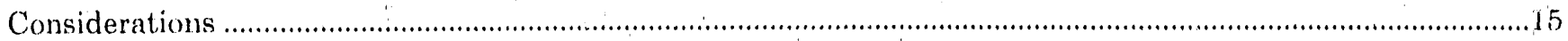

Surnmary

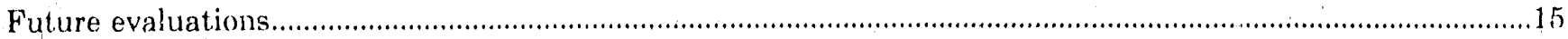

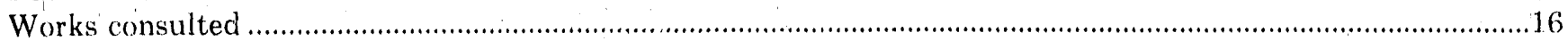

APPENDIX A-list of known commercially available outdoor lighting design programs................................17

A.PPENDIX B - The standard IESNA photometric file ..........................................................................19

\section{Figures}

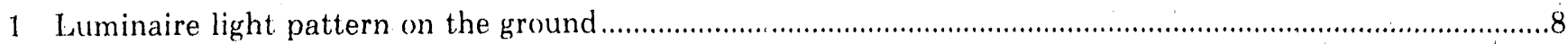

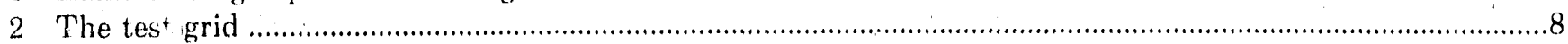

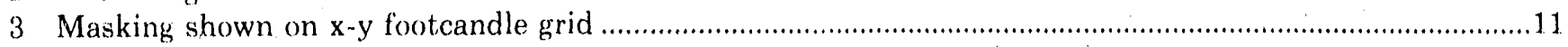

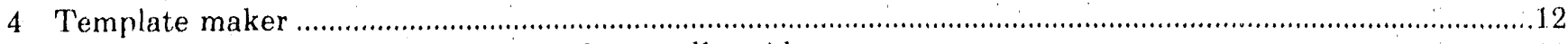

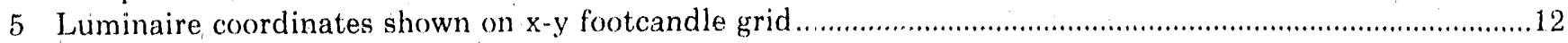

\section{Tables}

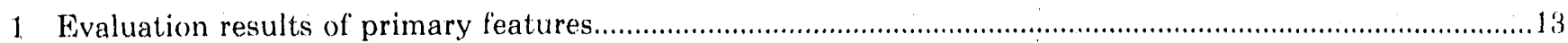

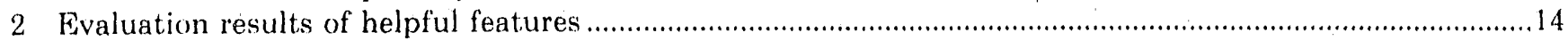

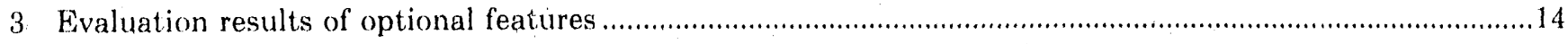




\section{Evaluation of Commercially Available Lighting Design Software}

\section{Introduction}

For years the lighting industry has manually entered and manually calculated the photometric data necessary for lighting designs. In recent years, lighting manufacturers and private lighting design software companies have published many computer programs to perform these calculations. Sandia $\mathrm{Na}$ tional Laboratories (SNL), as well as other organizations, is involved with outdoor lighting designs for closed-circuit television (CCYTV) requiring the use of lighting design software programs. Before commercial lighting design software programs were available, SNl, used a government agency's program and then developed an in-house program. The in-house program is very powerful but it has limitations, so it is not feasible to distribute it to other interested organizations. There is however still a demand for lighting design programs, so SNL is evaluating several of the commercially available programs (1) to determine if their features are adequate to aid the user in lighting designs and (2) to make this evaluation information available to SNI personnel, and to other organizations.

This report documents the results of evaluations performed. One of its objectives is to help users decide whether a program is needed and, if so, which one to choose.

\section{Safeguards and Security lighting design history at Sandia}

SNI, has been designing outdoor lighting for high-security perimeters for more than 14 years. 'This lighting was for exterior CCIV camera intrusion detection assessment. These CCTV cameras used a 1-in.-format silicon image tube. The illumination requirements (from a sodium vapor luminaire) are 1 footcandle minimum illumination and a maximum light-to-dark ratio of $6: 1$ in the camera's field of view.
Before computer modeling axisted, SNL built an exterior test-bed consisting of luminaires and a CCTV assessment system for each lighting project.

Figure 1 shows a luminaire installed next to a CCTV camera tower. Its illuminance is shown by the pattern at the bottom of the figure. This pattern can be thought of as the "footprint" of the luminaire. Illuminance values are in footcandles (fic).

Figure 2 shows these fo levels related to an $x-y$ coordinate grid with the $(0,0)$ coordinate in the lower left-hand corner. Each fo level shown on the bottom grid corresponds to a certain $x-y$ coordinate (specified in feet) as defined by the $x-y$ axis grid shown at the top of the figure.

Fstimates of fo levels were derived from lighting manufacturers' Isolux diagrams. The luminaides were then rearranged by types, mounting heights, spacing between poles, etc., until the illuminance values met the video requirements. Over time it became apparent that a better process was needed. In terms of time, equipment, and manpower, the test-bed approach was too costly. Computer modeling seemed to be the better process.

Unfortunately, SNL had no lighting design software program; at the time, none was commercially available. Later, a program borrowed from a government agency was used for a few years. This program was a slight improvement over the test-bed approach. About five years ago, an in-house program was written at. SNI, that performed all of the mathematical calculations previously done by hand. It also provided luminaire fo-level printouts in grid form plus many other unique features. This very powerful program was used in many security perimeter lighting layout. designs. Yet it was not distributed to other interested organizations for the following reasons:

- 'The program had been written solely for the HP-9000, Series 200) computer (98:36().

- There was no User's Manual.

- 'The user had to be quite knowledgeable about. lighting. 


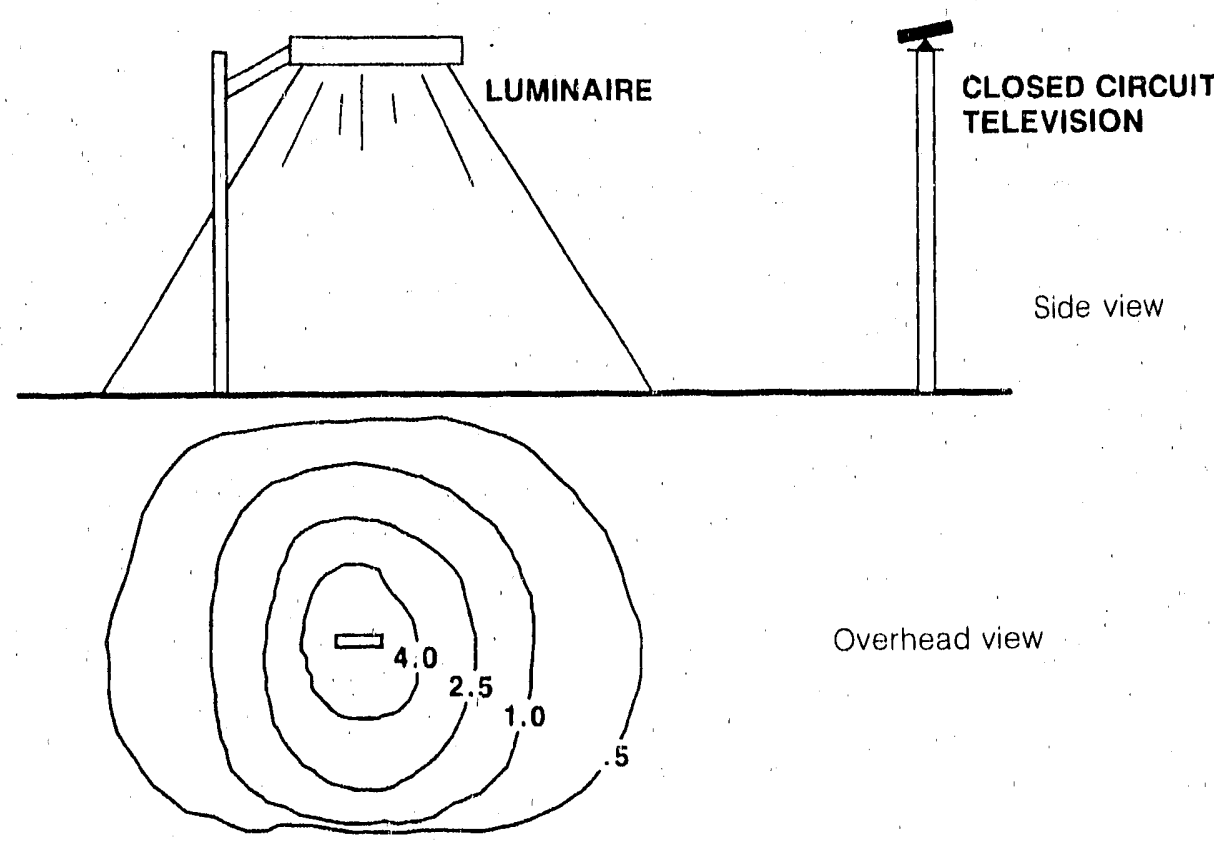

Figure 1. Luminaire light pattern on the ground (horizontal)

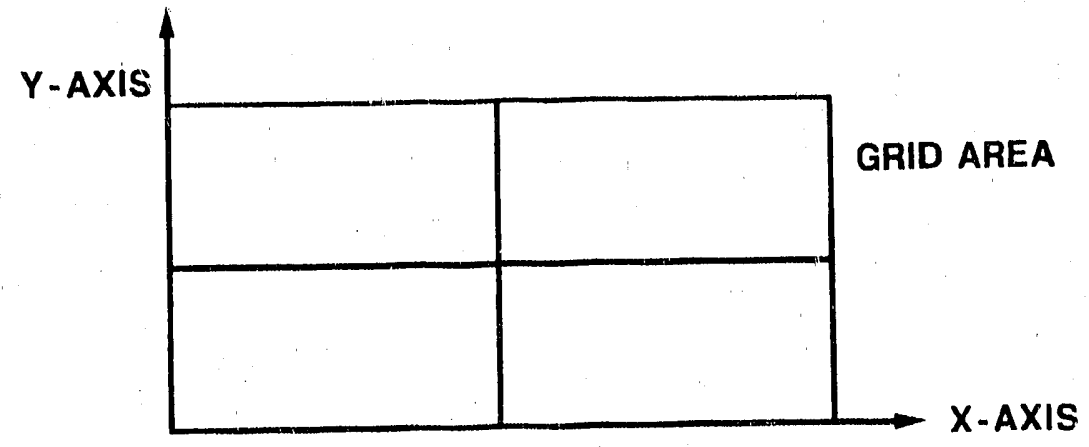

\begin{tabular}{|c|c|c|c|}
\hline & & & \\
\hline $\begin{array}{r}\text { Y.COURDINATE } \\
20.0\end{array}$ & 2.63 & 2.23 & 1.49 \\
\hline & + & + & + \\
\hline 10.0 & 4.68 & 3.37 & 1.85 \\
\hline & + & + & + \\
\hline 0.0 & 5.71 & 3.99 & 1.99 \\
\hline & + & + & + \\
\hline & 0.0 & 40.0 & 80.0 \\
\hline & & ORDI & \\
\hline
\end{tabular}

Figure 2. The test grid 
- The program was not suitable for standardformat photometric data tilles.

- All photometric data files had to be entered by hand:

SNL had a good lighting program, but few people could use it. Several organizations expressed an interest in obtaining their own lighting program. This has given us two options: to rewrite our program to be more compatible with other computer systems (specifically, the IBM PC) and accept a standard photometric data file format, or to determine if commercially available lighting design programs were suited to our needs. Time and manpower constraints led us to pursue the commercially available lighting programs, so they were sought out, ordered, and then evaluated.

As a service to the lighting community, the Computer Committee of the Illuminating Engineering Society of North America (IESNA) publishes a list of commercially available lighting design programs. This list has been reproduced in Appendix A. It is a complete listing of indoor, outdoor, and indoor/ outdoor programs. SNL is interested only in outdoor applications at this time, so companies specifying outdoor or indoor/outdoor programs were the only ones contacted.

IFSNA also provides a standardized format for lighting manufacturers' photometric data files. This can be found in Appendix B. All lighting manufacturers are encouraged to publish their data in this format, and lighting design program manufacturers are urged to write their programs to utilize the IESNA format for photometric data. The IESNA format will allow for universal use of all manufacturers' photometric data when all the lighting manufacturers publish their data in this format and all lighting design programs are written to accept this format. This will be a giant step toward standardization in the lighting industry.

\section{Evaluation equipment}

The computer system used for the evaluations was an IBM PC/AT with a $30 \mathrm{MB}$ hard-disk drive and $640 \mathrm{kB}$ of random-access memory (RAM); the Disk Operating System (DOS) was IBM Version 3.30. Peripherals attached to the computer were an NEC Multisunc color monitor and an HP Laserjet II printer. There was one high-density 5-1/4-in. floppydisk drive. For SNL's purposes, several lighting programs were installed on the IBM at the same time.

All the features included in the evaluation of the lighting programs will be discussed, and the more important ones will be explained in detail. A list of the programs evaluated and tables showing how they performed in the evaluation are also included in this report.

\section{Evaluation criteria}

\section{Primary features}

Items considered primary features for evaluation were

- IBM PC "compatibility

- acceptance of IESNA formatted photometric data files

- program accuracy

- user friendliness

- ability to adjust light-loss factors

- documentation, support or training, and program updates.

These features are described in greater detail below.

A program that can be installed on an IBM PC or an IBM-compatible PC could be used immediately in almost any business in America. Ideally, all lighting programs evaluated should be IBM-PC-compatible so that they can be utilized by a maximum number of end users. Some of the programs come with 5-1/4-in. disks; others come with 3-1/2-in. disks; and some programs come in both sizes. Either size can be specified when ordering most programs. All of the evaluated programs were IBM-compatible.

Programs having the ability to run IFSNA formatted photometric data files were desirable so as to make the end user's tasks easier and to help promote standardization of the photometric data file format in the lighting industry. For some programs, only specially formatted data files supplied with the program could be used. These programs were evaluated even if they did not accept IESNA formatted data files. However, a recommendation was made to the program manufacturer to publish a revised IFSNA format version as well. Unfortunately, when a lighting manufacturer publishes a program that accepts only its own photometric data format, the user must use that program in order to evaluate that company's luminaires. The IESNA format allows user access to an unlimited number of different brands of luminaires for project assessment. Most of the programs evaluated ran the IESNA format for photometric datu files.

Accuracy of the outputs from the evaluated programs was verified by shecking the conformity of a 
measure to a standard. The standard was an IESNA formatted photometric data file for a $180-\mathrm{W}$ lowpressure sodium luminaire. The measure was certain footcandle levels on a specifically laid out $x-y$ coordinate grid produced by using the standard's data.

The data for the standard was obtained by the manufacturer from an independent lighting testing laboratory. The tests performed on the luminaire provided candela values and isolux curves that became the photometric data for the $180-\mathrm{W}$ lowpressure sodium luminaire. The manufacturer used this data to provide the layout for the grid requested by SNI. for this luminaire. This layout was the standard to which the output layouts of all programs accepting its IESNA formatted photometric data were compared.

The layout of the $x-y$ coordinate grid with specified $m$ : nting heights, tilt, orientation, $x$ and $y$ coordinate, for luminaire placement, etc., was sent to the manufacturer of the luminaire chosen to be the standard. The manufacturer ieturned the grid in the requested format. The grid shows footcandle levels for the 180-W low-pressure sodium luminaire at spec. ified $x-y$ coordinates.

This specific grid layout was duplicated for all the evaluated programs accepting the standard's IESNA formatted photometric data files. The footcandle levels produced by the evaluated programs at the specified $x-y$ coordinates were compared to the corresponding footcandle levels on the standard grid. The degree of conformity of the footcandle levels of the evaluated programs to the footcandle levels of the luminaire chosen as a standard was then determined. Exact matches of fc levels, or within 1/100th of a footcandle, were seen with most of the programs. This accuracy check was for the mathematical formulas used to calculate illuminance levels from photometric data; the check was not for comparing program printouts to actual exterior installations using the standard luminaire. Accuracy of programs accepting only their own data could not be checked.

All lighting programs evaluated had to be userfriendly. This means programs presented in a format in which a user can just sit down and hegin working with it. One way to ensure this is to have menu-driven programs. A program in a user-friendly form allows input and responses back and forth between program and user. "This "give and go" is provided through menus and HELP' screens. All of the programs evaluated were user-friendly/menu-driven and had HELP screens.

Light loss of a luminaire can result for a number of reasons: dirt accumulation, lumen depreciation, ballast factor losses, or other adjustments made in the amount of light output. 'The light-loss factor is a number between 0 and 1 (where 0 is no light and 1 is full light) by which all candela values are multiplied. All of the programs evaluated made allowances for adjustments to the light-loss factor.

Documentation, support, and/or training are essential for the thorough understanding of a program. These factors also make a program user-friendly. All programs evaluated had to have a good User's Instruction Manual. This is especially important if no training is available, and some programs are so simple to use that no training is needed. However, several programs provide so many features that training would be necessary. 'Training classes are discussed in more detail in a later section entitled "Considerations." Support for the programs (telephone assistance and updates) is the mark of a reputable company. Support from local or district representatives is also helpful. Private lighting software firms provide support for their own programs. All of the programs evaluated had good documentation and support, and some offered excellent training classes. Updates of program changes were received from program suppliers on a timely basis. Some programs had no changes, so no updates were needed.

In addition to the basic features, there was such a wide variety of other features available that we think. it would be helpful to mention some of these additional features, and even describe some of them. These features are listed below under either "Helpful" or "Optional" features.

\section{Helpful features}

Listed and explained briefly are some of the other features examined in the program evaluations.

- Mass storage device. This enables a program to be run from the hard-disk drive and from floppy drives. Depending on one's computer system, this can be a critical need. For example, if the program can be run only on a hard disk, and the user has only a floppy-disk system, then the user cannot use this program. All of the programs we evaluated could be run from either type of drive.

- Math co-processor. All lighting programs should be operated on a computer system having a math co-processor, as this speeds up the large number of calculations necessary to run a lighting program. Many of the programs evaluated could not be run without a math co-processor; others recommend installing one to enhance the program's speed. 
- Program system configuration. This covers the requirements for computer and printer types, format for photometric data, level of DOS, RAM and disk-drive space, and math (:)processor. Most of the programs evaluated offered some form of program system configuration.

- Tilt. Tilt is the number of degrees above or below the horizontal luminaire position (usually $\left(0^{\circ}\right)$. Tilting of a luminaire was available on every program evaluated except one. This is a necessary feature for some projects and would prohibit the use of that program.

- Masking. Masking is used to block out objects (e.g., buildings and posts) within an area of interest (e.g., a security perimeter or parking lot). These objects are not desiralile for display, yet they are physically present. Only the general shape of the object is desirable for showing. There is no illumination on the ground where these objects occur, so the program does not print fo levels on the grid at the coordinates of the object. This helps portray the general shape of the object. Masking also prevents the program from printing zeros within the masked area; thus, it prevents the use of these zeros in the area calculations (e.g., $\mathrm{min} / \mathrm{max}$ levels and ratios) (Figure 3). All of the programs evaluated offered this feature.

\section{Optional features}

The following useful features are included with some of the programs.

- Template maker. Prints luminaire footprints in hardcopy form without running the entire program. Footprints can be made to any scale, cut out, and overlaid on the area of interest to estimate how many luminaires are needed (Figure 4).

- Luminaire estimator. This helpful tool takes a quick look at an area of interest to approximate the number of luminaires required without having to run the entire program. It has a few limiters, and it is not as precise in its estimates as the template maker.

- Hardcopy of worksheet.

- Usable with a digitizer (e.g., coordinates can be "picked" from a site map with a digitizer, instead of being input manually).

- Luminaire coordinates. 'These are shown on the $\mathrm{x}-\mathrm{y}$ f'c grid (Figure 5).

- User-designed, customized report headings.

- Editing of IESNA photometric data. Allows checking and editing of IESNA photometric data files.

- Cost. Some of the prograns are free; others cost up to $\$ 1200$.

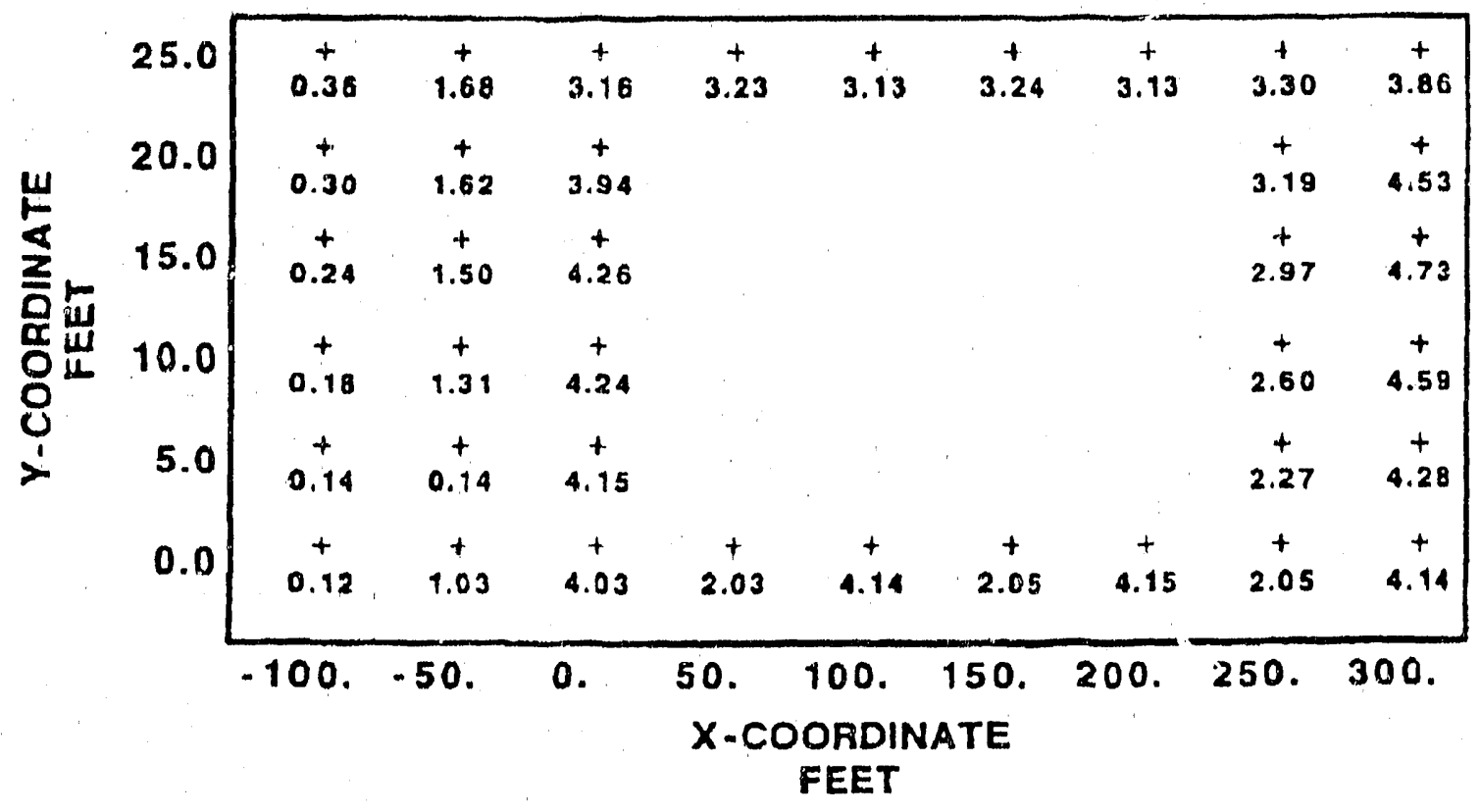

Figure 3. Masking shown on $x-y$ footcandle grid 


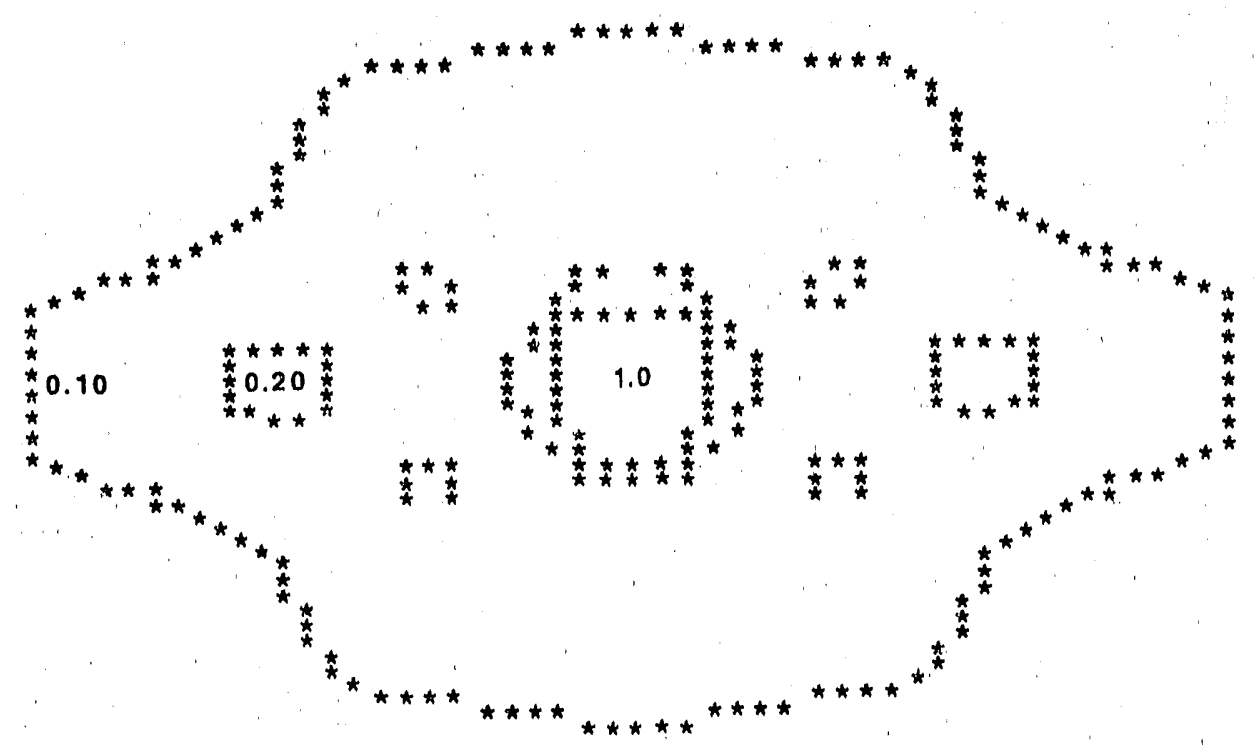

Figure 4. 'Template maker

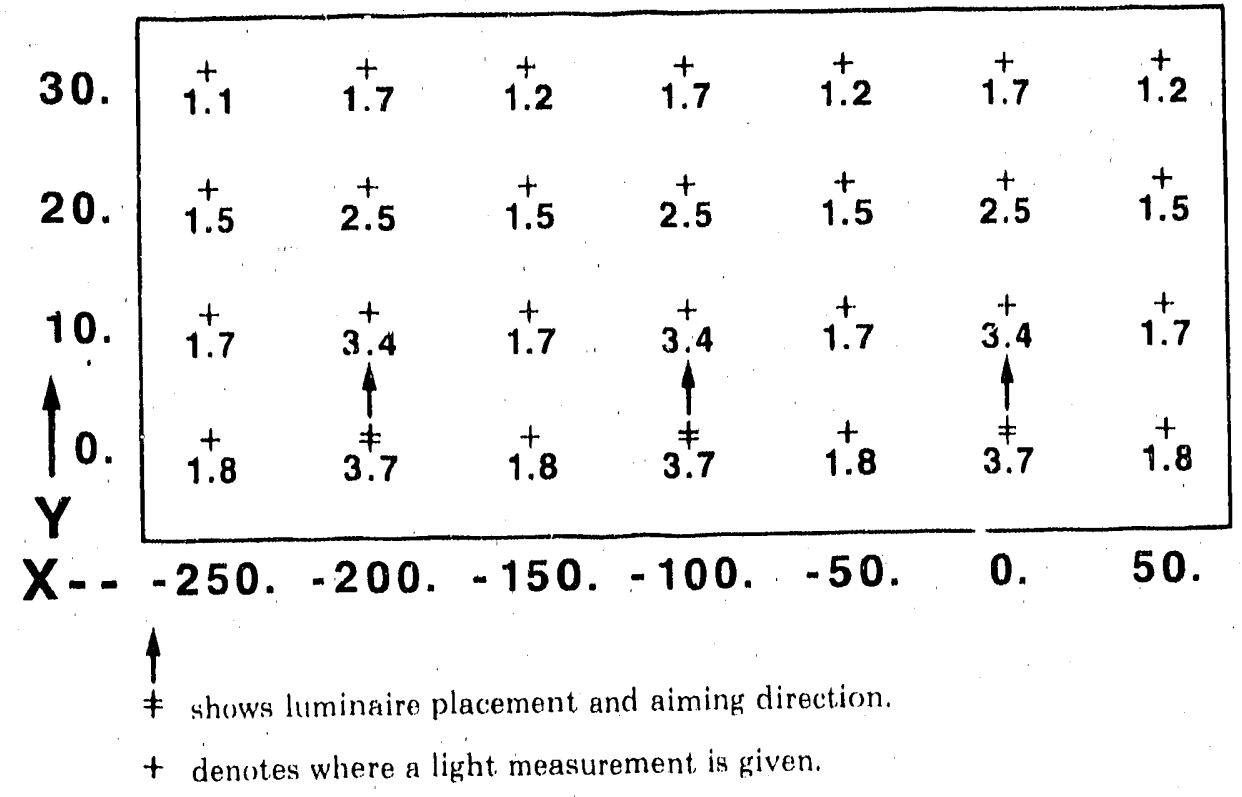

Figure 5. Luminaire coordinates shown on $x-y$ footcandle grid 


\section{Programs evaluated}

Listed below are the programs evaluated to date. Some were provided by lighting manufacturers, oth. ers by private lighting design firms. An asterisk (*) next to the program name indicates that the program came from a private lighting design firm.

\begin{tabular}{ll}
\multicolumn{1}{c}{ Program } & \multicolumn{1}{c}{ Source } \\
\hline CALA & Holophane \\
EMCO LI'IE & Emco Environmental \\
& Lighting, lnc. \\
LUMEN POIN'T* & Lighting Technologies \\
LUX 88 & Gardco Lighting \\
POIN'T* & Lighting Analysts, Inc. \\
Spaulding Lighting & Spaulding Lighting, Inc. \\
Applications Program &
\end{tabular}

\section{Evaluation results}

'Tables 1, 2, and 3 show the evaluation results of' the lighting programs. Every feature offered by each program is not listed in the tables. If a feature in which you are interested is not shown, contact the manufacturer of the program to inquire if that feature is off'ered.

Table 1. Evaluation results of primary features

\begin{tabular}{|c|c|c|c|c|c|c|}
\hline \multirow{2}{*}{$\begin{array}{l}\text { EVALUATION } \\
\text { CRITERIA } \\
\end{array}$} & \multicolumn{6}{|c|}{ PROGRAM NAME } \\
\hline & CALA & EMCOLITE & LUMEN PT & LUX88 & POINT & SPAULDING \\
\hline IBM COMPATIBLE & $x$ & $x$ & $x$ & $x$ & $x$ & $x$ \\
\hline IES FORMAT & $x$ & & $x$ & $x$ & $x$ & \\
\hline $\begin{array}{l}\text { PROGFAM } \\
\text { ACCURACY }\end{array}$ & $x$ & & $x$ & $x$ & $x$ & \\
\hline $\begin{array}{l}\text { LIGHT LOSS } \\
\text { FACTOAS }\end{array}$ & $x$ & $x$ & $x$ & $x$ & $x$ & $x$ \\
\hline USER FRIENDLY & $x$ & $x$ & $x$ & $x$ & $x$ & $x$ \\
\hline DOCUMENTATION & $x$ & $x$ & $x$ & $x$ & $x$ & $x$ \\
\hline SUPPORT & $x$ & $x$ & $x$ & $x$ & $x$ & $x$ \\
\hline TRAINING & $x$ & & $x$ & & $x$ & \\
\hline UPDATES & $x$ & 0 & $x$ & $x$ & $x$ & 0 \\
\hline
\end{tabular}


Table 2. Evaluation results of helpful features

\begin{tabular}{|l|c|c|c|c|c|c|}
\hline \multicolumn{1}{|c|}{$\begin{array}{c}\text { EVALUATION } \\
\text { CRITERIA }\end{array}$} & \multicolumn{6}{|c|}{ PROGRAM NAME } \\
\cline { 2 - 7 } & CALA & EMCOLITE & LUMEN PT & LUX 88 & POINT & SPAULDING \\
\hline $\begin{array}{l}\text { DISK DRIVE } \\
\text { FLEXIBILITY }\end{array}$ & $x$ & $x$ & $x$ & $x$ & $x$ & $x$ \\
\hline $\begin{array}{l}\text { MATH } \\
\text { CO.PROCESSOR }\end{array}$ & 0 & 0 & 0 & 0 & $\$$ & 5 \\
\hline $\begin{array}{l}\text { PROGRAM SYSTEM } \\
\text { CONFIGURATION }\end{array}$ & $x$ & $x$ & $x$ & & $x$ & $x$ \\
\hline TILT & $x$ & $x$ & $x$ & & $x$ & $x$ \\
\hline MASKING & $x$ & $x$ & $x$ & $x$ & $x$ & $x$ \\
\hline
\end{tabular}

5 must haVe to RUN progaAm

- suggested to have, but not mandatoay

Table 3. Evaluation results of optional features

\begin{tabular}{|l|c|c|c|c|c|c|}
\hline \multirow{2}{*}{$\begin{array}{c}\text { EVALUATION } \\
\text { CRITERIA }\end{array}$} & \multicolumn{5}{|c|}{ PAOGAAM NAME } \\
\cline { 2 - 7 } & CALA & EMCOLITE & LUMEN PT & LUX 88 & POINT & SPAULDING \\
\hline \hline $\begin{array}{l}\text { TEMPLATE } \\
\text { MAKER }\end{array}$ & $x$ & & & & $x$ & \\
\hline $\begin{array}{l}\text { LUMINAIRE } \\
\text { ESTIMATOR }\end{array}$ & $x$ & & & & & \\
\hline $\begin{array}{l}\text { WORKSHEET } \\
\text { HARDCOPY }\end{array}$ & & $x$ & $x$ & & $x$ & $x$ \\
\hline $\begin{array}{l}\text { DIGITIZER } \\
\text { LUMINAIRE } \\
\text { COORDINATES }\end{array}$ & $x$ & & & & $x$ & \\
\hline $\begin{array}{l}\text { CUSTOM } \\
\text { HEAOING }\end{array}$ & $x$ & $x$ & $x$ & & $x$ & $x$ \\
\hline $\begin{array}{l}\text { IES FORMAT } \\
\text { VERIFICATION }\end{array}$ & $x$ & & & & $x$ & \\
\hline COST & 595 & FHEE & 1195 & FREE & 345 & FREE \\
\hline
\end{tabular}




\section{Considerations}

The user is advised to consider the following in order to save time and avoid potential problems.

How often will a lighting design program be used? If the answer is rarely, let the lighting manufacturers perform the computer run for you. 'There is usually no charge for this service. A description of the area to be illuminated will be needed, and if yot: know which luminaire vou want to use tell the manufacturer. If you don't know, one will be recommended. The layouts for the project can be described to the manufacturer over the telephone, or they can be mailed or faxed. I have used this service several times and find it works well. I'rivate lighting design software companies also offer this service, but thera may be a charge.

'l he most difficult part of performing these evaluations was obtaining lighting manufacturers' photometric data files, in IESNA or other format, on floppy disks. 'There are two ways to obtain the data. One is by going through the lighting manufacturer's local or district representative. This proved successful with several of the companies I contacted. But, if this fails, request the service through the Application Engineering department at the lighting manufacturing company. Also, some of the p.ivate lighting design software developers can assist you. These people frequently work with lighting manufacturers and can furnisi contacts or give you copies of the data. Users should request manufacturers' photometric data files in IESNA standardized format on computer disks.

Many of the lighting design programs evaluated specify an Epson or Epson-compatible printer. I used an HP Laserjet Il printer. For a few of the programs, software to make the Laserjet. II printer emulate an Epson printer had to be installed in order to obtain a printout. 'The softiware I used was LuserControl by Hewlett-Packard. These printouts ar not as clear as those printed on an Epson printer; therefore, if possible, use a printer supported by the lighting program.

Your computer system should have an adequate amount of free hard-disk-drive space and RAM space. Most of these programs are large, and the data files can be huge. Plenty of space is necessary, especially if the user installs all of the photometric data on the hard-disk.

'Training classes are advisable. A fee is usually charged for this. The classes last 2 to 5 days, depending on the program.
'To obtain a list of' available computer lighting design programs, or other lighting information, write to:

\author{
Computer Committee \\ Illuminating Engineering Society of \\ North America \\ 345 East 47th Street
}

New York, NY 10017

In addition, IESNA publishes an informative monthly magazine called Lighting Ioesign + Application. It is free with an IESNA membership and may be available to nonmembers. Contact IESNA for details.

\section{Summary}

This report should give the reader enough information to decide (1) if a lighting design program is needed and (2) which program (or programs) would best satisfy the user's needs. 'There are many good commercially available lighting design programs. As can be seen by the tables, their features and costs vary considerably; but, with the information presented here, users should be able to choose a program based on their company's requirements.

If you are still unsure which program to purchase, demonstration programs are available. The cost is minimal (the programs I ordered cost up to $\$ 95$, but. some were free). A demonstration program leads the user through a sample lighting design project, using menus and worksheets, and produces a sample print out. The user is able to obtain a feel for the program's features. Demonstration programs can be especially helpful when trying to choose a complete program. Some programs are quite expensive, so it's important. to choose the appropriate one.

\section{Future evaluations}

Many outdoor lighting design programs are commercially available, and our evaluations are not com plete. SNL will continue to evaluate available outdoor lighting design programs and to document their features for interested organizations. 


\section{Works consulted}

Cahana, Michael '2. "The Use of Computers by Lighting Designers-Survey and Suggestions." Lighting Design + Application, June 1989.

Chasse', Robert. "The Role of the Computer in Lighting Design." Lighting Design + Application, June 1989.
Smith, D. A. An Exterior Lighting Design Program (Contractor report). SAND85-7245. Sandia National Laboratories, Albuquerque, NM, February 1986.

US Dept. of Transportation. Roadway Lighting Handbook, Addendum to Chapter Six. Addendum to Implementation Package 78-15, September 1983. 


\section{APPENDIX A}

\section{List of known commercially available outdoor lighting design programs}

\begin{tabular}{|c|c|c|}
\hline Program & & Manufacturer \\
\hline AUTOLUX & (R) & $\begin{array}{l}\text { Independent Testing Laboratories } \\
\text { 3386 Longhorn Rd. } \\
\text { Boulder, CO } 80302 \\
\text { Bill Brackett } \\
\text { (303) } 442-1255\end{array}$ \\
\hline CALA & (E) & $\begin{array}{l}\text { HOLOPHANE } \\
214 \text { Oakwood Ave. } \\
\text { Newark, OH } 43055 \\
\text { Greg Subisak } \\
\text { (614) } 345-9631\end{array}$ \\
\hline EMCO LITE & (E) & $\begin{array}{l}\text { EMCO Environmental Lighting, Inc. } \\
7300 \text { 50th St. } \\
\text { Milan, IL } 61264 \\
\text { Bob Gletty } \\
\text { (309) } 799-3111\end{array}$ \\
\hline L-2 & $\left({ }^{1}\right)$ & $\begin{array}{l}\text { Hauser's Lighting \& Daylighting } \\
128 \text { Bell Ave. } \\
\text { Piedmont, CA } 94611 \\
\text { Greg Hauser } \\
\text { (415) } 655-3158\end{array}$ \\
\hline LUMEN-POIN'' & (E) & $\begin{array}{l}\text { Lighting Technologies } \\
\text { 2540 Frontier, Suite } 107 \\
\text { Boulder, CO } 80310 \\
\text { Thomas Swanson } \\
\text { (30)3) 449-5791 }\end{array}$ \\
\hline LUX and LUME-STLT & $(\mathrm{R})$ & $\begin{array}{l}\text { Jolinko Enterprises } \\
8 \text { Lake Blvd. } \\
\text { Vicksburg, MS } 39180 \\
\text { Merle Keck } \\
\text { (601) 638-0484 }\end{array}$ \\
\hline (continued) & $(\mathrm{E})$ & $\begin{array}{l}\text { GARDCO } \\
2661 \text { Alvarado St. } \\
\text { San Leandro, CA } 94577 \\
\text { Ken Fairbanks } \\
\text { (415) } 357-6900 \text { or } \\
1-800-227-0758\end{array}$ \\
\hline
\end{tabular}




\begin{tabular}{|c|c|c|}
\hline Program & & Manufacturer \\
\hline MICRO-SITE-LITE & $(R)^{2}$ & $\begin{array}{l}\text { Lighting Sciences, Inc. } \\
7830 \text { E. Evans Rd. } \\
\text { Scottsdale, AZ } 85260 \\
\text { Richard Heinisch } \\
\text { (602) } 991-9260\end{array}$ \\
\hline P-LIGHT & (R) & $\begin{array}{l}\text { Richard Gehlbach } \\
3321 \text { Pepperhill Ct. } \\
\text { Lexington, KY } 40502 \\
\text { Richard Gehlbach } \\
(606) 2 \text { 6̂6-0531 }\end{array}$ \\
\hline PLANE & $(\mathrm{R})$ & $\begin{array}{l}\text { Illumination Computing Service, Inc. } \\
523 \text { Leda Lane } \\
\text { Arcadia, CA } 91006 \\
\text { Roy Jones } \\
\text { (818) 574-9695 }\end{array}$ \\
\hline POINT & (E) & $\begin{array}{l}\text { Lighting Analysts, Inc. } \\
10572 \text { E. Park Mountain Rd. } \\
\text { Littleton, CO } 80127 \\
\text { David Speer } \\
\text { (303) } 972-8852\end{array}$ \\
\hline ROADWARE & (R) & $\begin{array}{l}\text { ELITE Software Development, Inc. } \\
4444 \text { Carter Creek Pkwy. } \\
\text { Bryan, TX } 77802 \\
\text { Tim Wilcox } \\
\text { (918) 585-1826 }\end{array}$ \\
\hline $\begin{array}{l}\text { SPAULDING } \\
\text { LIGHTING } \\
\text { APPLICATIONS } \\
\text { PROGRAM }\end{array}$ & $(\mathrm{E})$ & $\begin{array}{l}\text { Spaulding Lighting, Inc. } \\
1736 \text { Dreman Ave. } \\
\text { Cincinnati, OH } 45223 \\
\text { Vicki Weems } \\
(513) 541-3486\end{array}$ \\
\hline \multicolumn{3}{|c|}{$\begin{array}{l}\text { (E) denotes programs evaluated. } \\
\text { (R) denotes programs received but not yet evaluated. }\end{array}$} \\
\hline \multicolumn{3}{|c|}{$\begin{array}{l}{ }^{1} \text { Disparities between SNL's Legal department and Mr. Hauser's attorney } \\
\text { on the software use licensing agreement could not be resolved; therefore, } \\
\text { we were unable to order L-2. } \\
{ }^{2} \text { Represented by Murray \& Gillespie Computing Solutions }\end{array}$} \\
\hline
\end{tabular}




\section{APPENDIX B}

\section{The standard IESNA photometric file}

The Illuminating Engineering Society of North America has developed a standard format for the exchange of photometric data. The specifications for this file are presented here.

The standard photometric file is organized in the following manner: Each line marked with an asterisk inust begin a new line. Descriptions enclosed in " $<$ " and " $>$ " refer to the actual data stored on that line. All data is in standard ASCII format.

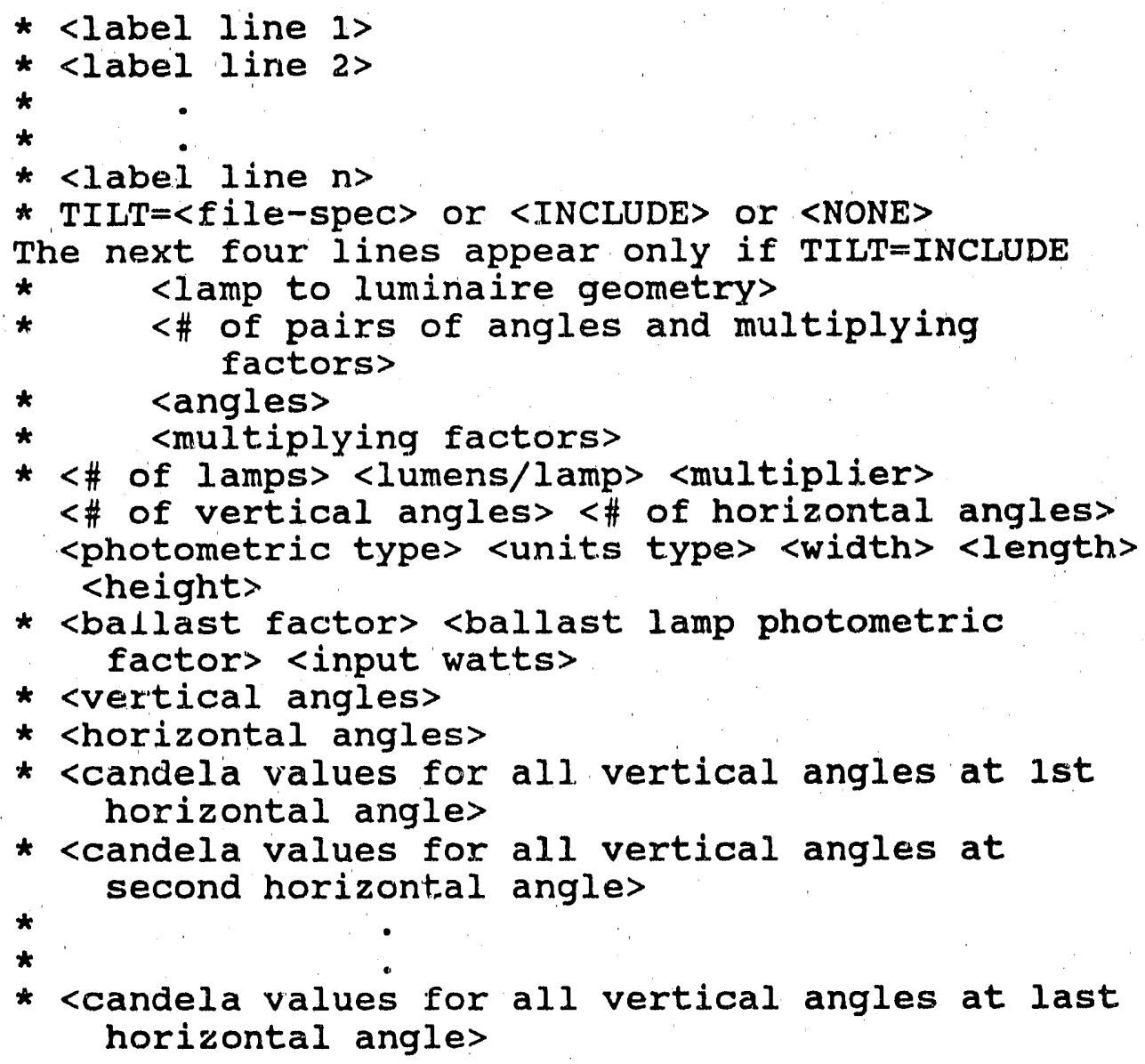

Each of the items listed above is defined and input as follows:

$<$ label line $>-$

Line of descriptive text that describes the luminaire in the file. Each label line may contain up to 80 characters.

$\mathrm{TILT}=<$ file-spec $>-$

This line directs an analysis program to a data file describing how the luminaire/lamp output varies as a function of the tilt angle. <file-spec $>$ is the name of the file containing this information. This name may be no more than 75 characters. 
TILT $=$ INCLUDE should be used if the angles and multiplying factors are included as part of the complete photometric file. The format for this information is the same whether it is in a separate file or included as part of the photometric file. It is shown below:

$<$ lamp to luminaire geometry $>-$

This indicates the orientation of the lamp within the luminaire, and should be the value 1,2 , or 3 , according to the following schedule:

1 When the luminaire is aimed straight down, the lamp is either vertical base up or vertical base down.

2. When the luminaire is aimed straight down, the lamp is horizontal, but when the lamp is tilted in the 0-degree horizontal plane, the lamp tends to a base-up or base-down condition as a result of the luminaire tilt.

3 When the luminaire is aimed straight down, the lamp is horizontal and remains horizontal when the luminaire is tilted up in the 0-degree horizontal plane.

$<\#$ of pairs of angles and multiplying factors $>-$

The total number of pairs of angles and corresponding multiplying factor.

$<$ angles $>-$

The angles should be listed in increasing order, and should go from 0 to 90 degrees or from 0 to 180 degrees, inclusive. 0 degrees corresponds to the multiplying factor to be used when the luminaire is aimed straight down.

$<$ multiplying factors $>-$

The multiplying factors should be listed in the order corresponding with the angles given in the line above.

NOTE: the phrase 'TILT $=$ ' must begin in Column 1 and contain no blank characters. This is important since this phrase is used to signify the end of the label information. If the output of the luminaire/lamp combination does not vary as a function of the tilt angle, then TILT $=$ NONE should appear in the file.

$<\#$ of lamps $>$ -

This is an integer equal to the number of lamps in the luminaire.

$<$ lumens/lamp >-

This is an integer equal to the number of rated lumens per lamp on which the photometry is based.

$<$ multiplier $>$ -

This is a factor that must be applied to all candela values in the file. It will usually be equal to 1 .

$<\#$ of vertical angles $>-$

This number is an integer equal to the number of vertical angles in the photometric report.

$<\#$ of horizontal angles $>-$

This number is an integer equal to the number of horizontal angles in the photometric report.

$<$ photometric type $>-$

This number is an integer indicating the type of photometry that exists for the luminaire being described. A ' 1 ' corresponds to Type A photometry, and a '2' corresponds to Type B photometry. 
$<$ units type $>-$

This is an integer indicating the type of units used in the report. A ' 1 ' is used if the units are given in feet, and a ' 2 ' is used if the units are given in meters.

$<$ width $>-$

This number is the distance across the luminous opening of the luminaire in the 90- to 270-degree plane.

$<$ length $>$

This is the distance across the luminous opening of the luminaire in the 0- to 180-degree photometric plane of the luminaire.

$<$ height $>-$

This distance is the height of the luminous opening of the luminaire.

$<$ ballast factor $>-$

This is a loss factor caused by the difference between the operating ballast and the standard (reference) ballasting specified for rating lamp lumens.

$<$ ballast lamp photometric factor > -

This is a loss factor due to the difference of using a given ballast and lamp type under photometric test conditions to that of the same luminaire with the ballast and lamp type used to generate a photometric report.

$<$ total input watts > -

This is the value of the total watt input to the luminaire, including ballast watts.

$<$ vertical angles $>-$

The vertical angles in the photometric report should be listed on the appropriate line in the file, in increasing order. For Type A photometry, the first value must be either 0 or 90 degrees, and the last value must be either 90 or 180 degrees. For Type B photometry, all angles must be between -90 and +90 degrees, inclusive. If the first value is equal to zero, symmetry will be assumed to exist between the top and bottom halves of the luminaire.

$<$ horizontal angles >-

The horizontal angles in the photometric report should be listed on the appropriate line in the file, in increasing order. For Type A photometry, the first value must always be either 0 or 90 degrees, and the last value must be either $0,90,180$, or 360 degrees. For Type B photometry, all angles must be between -90 and +90 degrees, inclusive. If the first angle is equal to zero, symmetry will be assumed to exist between the left- and the right-half field of the luminaire's photometry.

$<$ candela values for all vertical angles at $n^{\text {th }}$ horizontal angle >-

This is a list of the candela values in each vertical plane of photometry. The candela values for each vertical angle are listed for successive horizontal angles. The order of the angles must. be in increasing order, exactly as the angles appear in the previous lines of the file.

The following rules must be followed to construct a standard photometric file?

- The individual values on any one line should be separated by a space or a comma.

- Any of the data lines specified above may be continued on an additional line (or lines), if necessary.

- No line is permitted to exceed 132 characters. 
- Where more than one luminaire is present in a standard format file, the first label line of any subsequent luminaire should immediately follow the last line of candela values for the previous luminaire.

An example file is shown below.

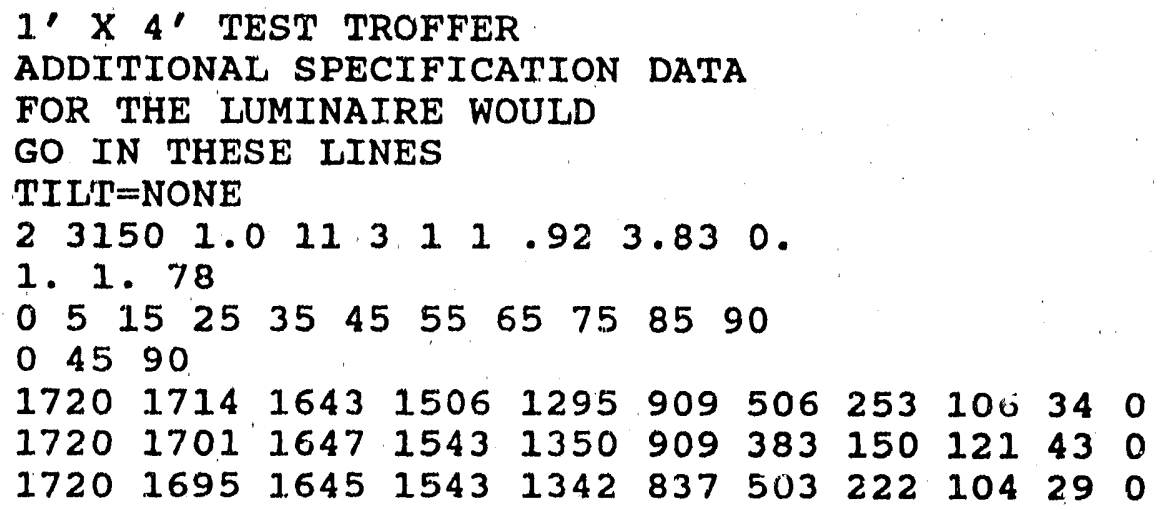



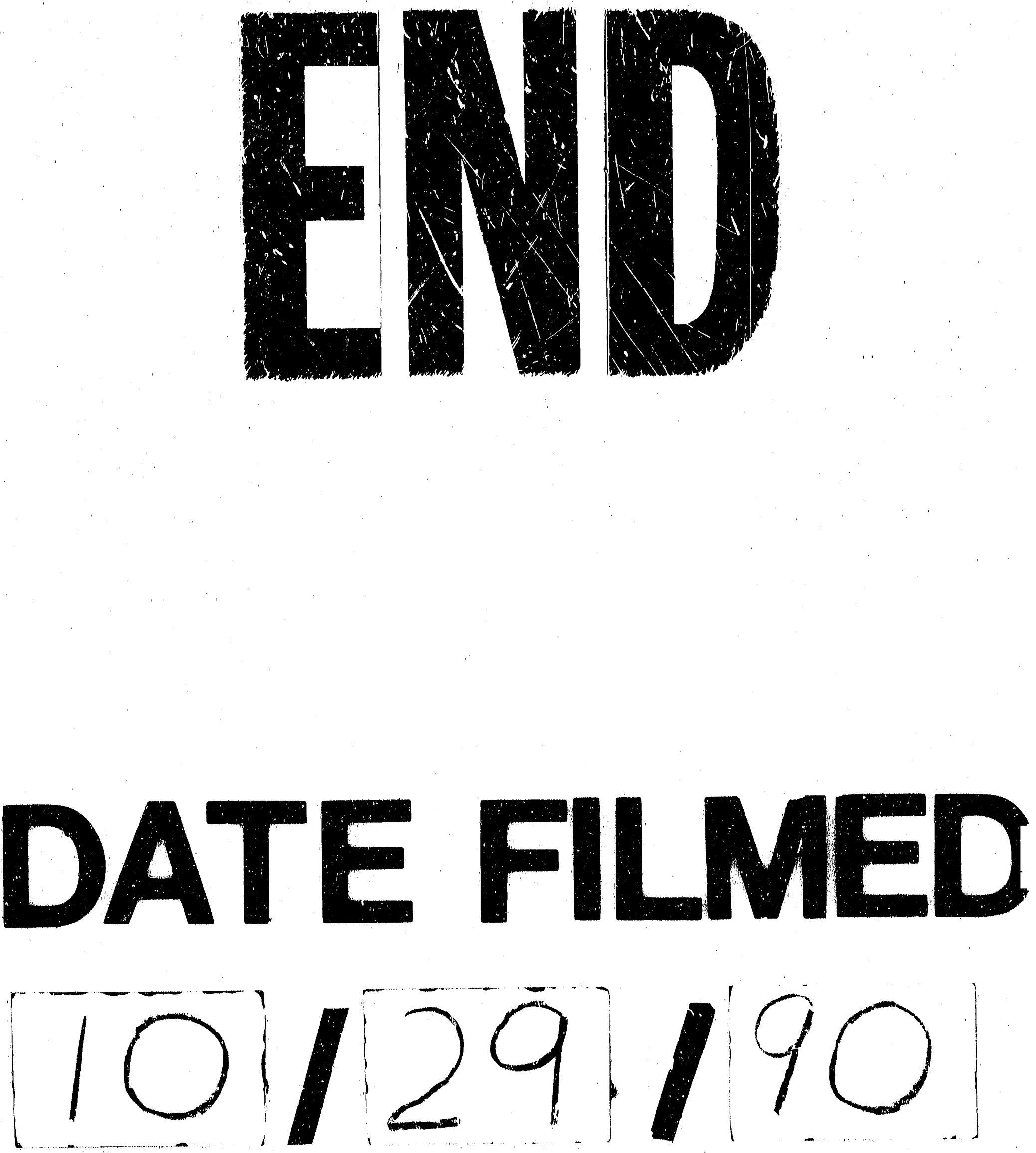
